\title{
Aclarando la mirada de investigación desde un caleidoscopio: Meraki de humanización
}

"Comprender textos es conversar con ellos, mantener un diálogo en que les preguntamos y ellos responden, y sus respuestas son, a su vez, preguntas dirigidas a nosotros mismos"

Gadamer (1995)

\begin{abstract}
gradezco al lector su tiempo, disposición e interés al emprender un nuevo viaje de lectura con sentido, en el que espero, pueda encontrar un diálogo
hermenéutico con los autores de esta edición número 2 del volumen 17 de la Revista Colombiana de Rehabilitación. En el marco dialógico que propone Gadamer, el lector tiene el permiso de crear y recrear todas las riquezas que surgen de la capacidad de indagar, cuestionar, preguntar y ampliar el horizonte de interpretación, a partir del hilo de sentido de los diversos autores que comparten con nosotros sus resultados de investigación.
\end{abstract}

Los profesionales que abordan temas de rehabilitación tienen la necesidad de cubrir un espectro importante de cuestiones, siempre vinculadas a la complejidad humana; en tal sentido, desarrollan metodologías y conocimientos, de cara a la comprensión de las diversas realidades que se concretan fundamentalmente en lo corporal y en lo social. Dichas realidades son aprehensibles desde diferentes perspectivas, que transitan desde la reflexión misma en las profesiones, hasta la medición y el desarrollo tecnológico para la rehabilitación humana. Cada uno de los artículos es inmensamente enriquecedor y está cuidadosamente desarrollado desde un enfoque riguroso de investigación.

Quiero aprovechar mi experiencia y la fortuna, durante los últimos 15 años, de trabajar con diversos profesionales de distintos sectores económicos, incluido el sector salud, en procesos que incluyen la toma de consciencia del servicio y atención desde un enfoque de humanización. Con esto, invitar al lector y a los próximos autores de la Revista Colombiana de Rehabilitación a incluir en sus investigaciones, intervenciones e interpretaciones, desde este enfoque, puesto que a partir de ese lugar podemos conversar de la importancia, necesidad y urgencia ética que trae consigo la forma en que percibimos, interactuamos, enunciamos y nos aproximamos a lo humano en nuestro ejercicio profesional, incluida la investigación.

El título de esta editorial trae consigo dos términos: caleidoscopio, cuya etimología proviene del griego, es resultado de la suma de los componentes "kálos" que es sinónimo de "bello" "eidos" que puede traducirse como "imagen" y la palabra "Skopein" que es equivalente a "ver"; es decir, ver imágenes bellas y hermosas. Meraki, es una palabra griega que no tiene una traducción simple a otros idiomas, tal como lo plantea Alex Wain en el diccionario de lo intraducible. La palabra expresa más una idea compleja que un concepto concreto, es algo así como hacer algo "desde el alma", dedicando empeño, transmitiendo amor o un fuerte sentimiento en cada uno de los gestos, creando un ambiente idóneo para desarrollar la creatividad y conseguir algo diferente donde estemos reflejados nosotros mismos.

En este orden de ideas, enfocarnos a ver desde un caleidoscopio, es una analogía para darnos cuenta de la multitud de detalles que muchas veces pasamos por alto, que son necesarios para comprender, o por lo menos para poder acercarnos a la realidad o situación que deseamos investigar, y mucho más, cuando nuestro foco de interés se centra en el ser humano, donde no puede faltar el "meraki" que nos lleva a relacionarnos, mirar, servir y a investigar con humanización, contando con la capacidad permanente de asombro, curiosidad, cuidado, creatividad y elegancia; para brindar, éticamente en cada momento, esa apuesta o promesa de valor que da sentido y huella a la dignidad y al trato humano.

Sin embargo, es paradójico tener que hablar y llevar la mirada al tema de humanización, si se supone que es algo indisoluble en nosotros, algo inherente a lo humano que precisamente nos hace únicos y nos caracteriza, pero es evidente que a lo largo de la historia existe una tendencia cada vez más fuerte y con más tonalidades de tensión, que nos ha llevado a relacionarnos de una manera ausente de lo que somos y de lo que representamos, en algunos casos con una fuerte indiferencia, desvalorización y despersonalización, haciendo que se pierdan o desdibujen en alguna medida los principios fundamentales cuando nos relacionamos con otro ser humano.

La invitación entonces es volver a lo fundamental, a lo que se supone, forma parte de nuestro ser ético y bioético, que nos vincula con otros pero que a la vez nos diferencia, a eso que cobra acción en la comunicación humana, a ese sentido y significado de la humanización.

Para ello, podemos identificar en Colombia tres tendencias, ejes o focos de estudio en donde se ha vinculado la importancia de la humanización, el primero es el eje político que busca crear discursos cada vez más humanizados para resignificar, entender y habitar el proceso de paz e inclusión en Colombia; el segundo, en la pedagogía-enseñanza de la educación, en donde el interés es trabajar en la formación de competencias ciudadanas, las cuales se espera, evidencien eso humano que se diluyó en el camino y requiere con urgencia de un especial manejo y cuidado en la sociedad actual; 
y tercero, el eje relacionado con el tema de salud, hablar de humanización en este espacio para la mayoría de los casos se ha reducido a comprender y potencializar la forma en que se establecen las relaciones, en crear lazos de empatía y compasión, con inspiración de personas altruistas con reflejos y actitudes de calidez humana en el servicio y la atención.

Posiblemente esa sea una causa que hace que en muchos casos sobre todo en el ambiente hospitalario o en los escenarios relacionados con la rehabilitación, exista por lo menos la enunciación de la promesa de valor en el servicio, el cual deja ver la asistencia sistemática y rutinaria de los profesionales del área de la salud, lo que hace que las instituciones realicen esfuerzos cada vez más grandes y soportados desde un sistema de gestión sólido, que sea reflejo, entre muchas cosas, de procesos, protocolos, tecnologías, programas, recursos, en una sola palabra, ser reflejo de calidad, dejando muchas veces en segundo lugar los aspectos relacionados con la calidez, que tienen que ver entre otros, con el afecto, gentileza, cuidado, compasión, empatía, buenos modales, trato y actitud, aspectos importantes en la creación de experiencias dignas de ser recordadas en la atención humanizada.

Teniendo en cuenta lo anterior, quiero ilustrar la reflexión en tres direcciones que se complementan entre sí y se desarrollan en el ejercicio de las profesiones. La primera dirección la llamaremos aprendiendo a sufrir o comúnmente conocida como cosificación. Es la situación que ocurre cotidiana y rutinariamente cuando enunciamos al otro como una categoría, una etiqueta, un estado, una situación, un diagnóstico, una parte, una estructura, una función, una dolencia, una carencia, un portador, un objeto a ser medible, cuantificable, en donde el todo (lo que él es y representa) se desdibuja en una parte (categoría o estructura de estudio), en una frase pasando de sujeto a objeto. Para ilustrar mejor la idea anterior y facilitar la claridad, me voy a permitir citar diálogos de la película amar la vida/Wit (2001) de Mike Nochols, la cual invito a ver a la luz del caleidoscopio de la humanización.

- Estoy aprendiendo a sufrir... dijo ella, luego de un día cotidiano de exámenes.

"Es ligeramente incomodo hacerse un electrocardiograma, pero la agonía de una colonoscopia lo borra de la memoria. Al principio fue vergonzoso estar en camisón todo el día, pero luego me pareció un gran privilegio comparado con ver como me quedaba calva y que un exalumno mío me hiciera un examen pélvico... fue bastante degradante... pero jamás me hubiera imaginado la profundidad de la humillación“.

La segunda dirección la llamaremos no me pagan para eso o comúnmente conocida como ausencia de interés. Es cuando encontramos profesionales que pierden su vocación o por lo menos se distancian de ella, y en sus prácticas profesionales y con el trabajo en equipo no manifiestan una actitud que permite la empatía, la calidez y la compasión en la atención y en el servicio.

- Ella pensó: soy una gran pérdida de tiempo para los investigadores...

"Estamos hablando de vida y muerte, pero no en abstracto de mi vida y de mi muerte; no es tiempo de argüidas verbales, erudición, interpretación, complicación. Es tiempo de simplicidad... de interés... de bondad.

La última dirección la llamaremos no tengo tiempo para esto o comúnmente conocida como distanciamiento afectivo. Si bien, es cierto que nos han implantado la idea de no vincularnos o asociarnos en la atención, con el propósito de no salir lastimados en esa relación profesional - paciente, con el paso del tiempo es visible que muchos se camuflan en esa idea, con todo lo que ello implica, de manera poco favorable en los procesos de recuperación, de asimilación y aceptación de una condición de salud muchas veces desafortunada, tanto para quien padece la situación como para su sistema familiar, en donde el tiempo y la experiencia que se vive requiere de toda la afectividad posible, desde el trato y cuidado humano.

- Dos días sin comer y ella no entendía ¿qué quedaría por vomitar?...

"No pueden imaginarse lo inmóvil que puede llegar a ser el tiempo. Se detiene, adquiere peso, y sin embargo, hay tan poco, se va tan lentamente y sin embargo... es tan escaso".

Luego de permitirse disfrutar la mirada en el caleidoscopio a través de estos apartes de la película y de transitar entre líneas sobre la importancia de resignificar e incluir el valor de la humanización, sobre todo cuando estamos interesados en realizar procesos de investigación, espero que tenga presente que cuando trabajamos y nos relacionamos con otros seres humanos, por ejemplo al hacerlo en el área de rehabilitación, debemos desarrollar conscientemente la capacidad de darnos cuenta, y de develar a través del lenguaje esas representaciones e imaginarios del mundo simbólico que le permiten al otro (al que quiero investigar) ser y estar en el mundo, esto ayudaría a que la investigación incluya en su discurso, una discusión con una mirada de unicidad, integralidad e indisolubilidad del ser humano, alejándonos de la fragmentación, del desinterés y de la desvalorización, con un alto sentido de propósito bioético, desde un enfoque de humanización que rescata la dignidad del otro como sujeto de derechos.

Finalizo reconociendo con absoluto respeto, admiración y gentil afecto a todos esos niños y niñas, quienes habitan los adultos presentes en este diálogo que habitamos en estas letras vividas. Espero se asombren, sonrían y se den permiso de descubrir tímida, rigurosa, apasionada y propositivamente lo maravilloso de cada artículo de la revista; y que a partir de allí elijan mirar por el caleidoscopio de la investigación, en donde todo es posible, con una variedad de caminos que incluyen tácita e indisolublemente el sentido y significado de la humanización.

\section{Maribel Chitiva Cardona}

Profesora Fisioterapia

Escuela Colombina de Rehabilitación 